\title{
A PROPOSAL FOR A CURRICULUM IN BEHAVIORAL BIOLOGY AND MEDICINE IN MEDICAL SCHOOLS
}

HERBERT WEINER, M.D.

\begin{abstract}
A curriculum in behavior for medical students is proposed that has several aims in mind: 1) To help students synthesize the diverse disciplines taught in the first two years using the integrative approach of behavioral biology using the familiar language of physiology. 2) To provide them with an unified concept of health, illness and disease. 3) To acquaint them with the varieties of ill-health in order to counteract the bias that only structural disorders-disease-causes it. At the same time they should be taught non-pharmacological approaches to treatment. 4) To acquaint them in the third year with the broad range of illness and disease, in settings which do no only house terminally or exotically sick patients. 5) To reach the skills explicitly that make for the recognition of distress in patients: compassion can be taught in the manner of any other skill.
\end{abstract}

\section{INTRODUCTION}

The flurry of recent publications on medical education ${ }^{1-6}$ attest to a recurrent crisis with a 10-15 year cycle, manifested by conference reports. A comparison of the present and past reports, inclines one to the view that nothing much has changed, or is likely to do so. But how could it? The political and academic structúre of medical schools is invariant, the teaching of medical students is a low priority in academic medicine ${ }^{7}$, and little thought is given to educating (rather than teaching) students how to think as doctors.

Medicine continues to be defined as a mysterious brew of "compassion and reductionism." A recent symposium entitled, "On the Training of Tomorrow's Physicians" 6 says nothing coherent about the bureaucratic, and mechanized tomorrow that is already here today-the impact that for-profit hospitals, DRG's, and computerized diagnoses, etc., already have, and will have in the future, on medical education and practice. And yet, the

Dr. Weiner is Professor of Psychiatry \& Biobehavioral Sciences and Chief of Behavioral Medicine at University of California, Neuropsychiatric Institute in Los Angeles.

This proposal was presented at the Annual Meeting of the Academy of Behavioral Medicine Research, Symposium on Medical Education, Kiawah Island, South Carolina, June 2 - 5, 1985. 
multiple tensions and contradictions that abound in academic medicine paralyse any attempt to change the education of students.

The education of medical students is also tied to the incoherence of a system by which they are selected - by a reliance on grades and MCAT scores (when it is already known that these are in part obtained by dishonesty $^{8}-\mathbf{a}$ fact with the consequence of misconduct on the part of physicians. ${ }^{9}$ It is also determined in large part by the content of National Board examinations. Students in short are picked to pass exams, not for those qualities which make for good physicians.

Additionally, the process of educating students is not guided by an overall theory or goal except in the most general terms. In operation, it is splintered into special areas of study ${ }^{6}$ which are defended to the death by specialists who consider their field as preeminent for the student's education. The student never gets an overview of medicine and how it fits into the scheme of things, of nature and society. Students receive piecemeal information; they are not taught a unified theory of health, illness, and disease, or a patient-oriented rather than a disease-oriented theory of disease. They remain uninstructed about the nature and kind of ubiquitous complaints for which most patients seek help. Most patients they will see are ill (e.g. are anxious, or have headaches, etc.), "or they are pregnant. They do not have diseases. Yet most of the medical education is narrowly focused on searching out the nonexistent molecular and cellular basis for their ill-health, as if it were invariably the product of disease, when it is not. The recognition of illness without disease is not taught. Nor are students taught what questions to ask so that they can elicit a history of such illnesses - they are wholly innocent about a "medicine without signs," in Lloyd's ${ }^{11}$ phrase.

Not to know how to ask the right question, and then to seek out the correct answer, based on existing knowledge, begins at the very start of medical school. The preclinical curriculum (taught so frequently by nonclinicians) in addition to being fragmented exists in a vacuum. Students complain that they have no idea of the reasons for being taught an unending array of detailed facts. They see only dimly the relevance of immunology, endocrinology, virology, metabolism, biochemical genetics and molecular biology to diseases about which they do not yet have any knowledge. What is the question, they ask, to which the answers are provided? In fact, they do not see patients until after they learn details, soon forgotten, and are taught by different departments and at different times in their careers.

No attempt is made to integrate these scattered facts into an overall scheme already touched upon, or alternatively integrated around the concept of the central role of the brain in regulating and monitoring every bodily organ and its function. But the brain also receives and processes inputs from the environment and responds to them with the appropriate behaviors. (In fact, the medical curriculum is structured in such a 
mannner that the outside observer would get the impression that behavioral and organismic biology did not exist as one of the two main pillars of modern biology [the other being molecular biology], and hence of medicine.)

\section{CURRICULUM PROPOSAL}

Therefore, one proposal would be to introduce behavioral biology into the curriculum, around which much of the material of the first year could be integrated. By behavioral biology I mean the biology of those vital functions that allow the organism to survive in its environment. These functions are disturbed in ill-health, and in disease. Such a course integrates material from many disciplines. It is not designed to supplant them.

\section{The First Year}

Specifically, the content of the first year curriculum should be:

I. The Biology of Food and Water Intake: Medical Significance.

A. The Biological Significance of Food Intake.

$<$ Short term and Long term requirements. $>$

B. Feeding is not only a matter of ingestion.

Food seeking, predation, food gathering, storing, eating.

C. Role of odors, taste, sight.

Aversive learning. The psychic phase.

D. Peripheral mechanism - the Infant Rat.

Attachment \& feeding

Sucking

Milk let down

E. Mechanism of Satiety and Feeding.

1. Neural, humoral and peripheral mechanisms.

2. Medullary, pontine, midbrain relays.

3. The hypothalamus-

a. Integration

b. Effects of VMH \& LH lesions.

Immediate and long-lasting effects on behavior and body. Recovery.

c. Catecholamines and Monoammines.

Peptides (CCK, Bombesin, Substance P, TRH, Somatostatin, Enkephalins and Endorphins.)

Amino acids.

Fatty acids. 
GABA.

Insulin

Sex hormones.

d. Regulation of carbohydrate intake.

e. Role of amygdala and septum.

f. Models of obesity and of anorexia.

F. Water Intake. Medical Significance.

1. Thirst, and drinking behavior.

2. Osmotic pressure: The role of sodium.

3. Osmoreception and osmoreceptors.

4. Cellular dehydration. Hypovolemia. Angiotensin II (AII)

5. Relative roles of osmoreceptors \& AII

6. Vasopressin.

7. Water intoxication.

8. Mechanisms of drinking behavior.

Physiology

Social factors.

Alcohol intake.

II. The Biology of Sleep and Waking.

A. Relevance for Medicine.

B. The waking EEG.

1. Alpha rhythms

2. Alpha blocking

3. Delirium, stupor and coma.

C. The sleeping EEG.

1. Sleep stages: ontogenesis.

2. REM periods.

3. Dreaming.

4. Mechanisms.

D. Physiological Correlates of Sleep.

1. Spinal mechanisms.

2. Temperature

3. Hormonal Rhythms

Melatonin

Catecholamines

Sex hormones

Prolactin

Cortisol

E. Sleep deprivation: Effects.

F. Jet Lag: Effects on behavior and physiology. 
G. Circadian Rhythms.

Role of oscillators.

"Zeitgebers".

III. The Biology of Sexual Behavior including mating.

A. Relevance for medicine.

B. Sexual differentiation.

Genetic Factors.

Anatomical Factors.

Hormonal Factors.

Social factors - learning.

Rearing: heterosexual. isosexual.

C. Sexual dimorphism. Hermaphroditism.

D. Puberty - Hormonal factors.

Secondary sexual characteristics

1. Pheromones - olfaction.

Tactile stimulation.

Temperature and light.

2. Lordosis behavior.

Hormonal factors.

3. Mating behavior.

Neural mechanisms.

Hormonal mechanisms.

Neuromuscular mechanisms.

4. Estrus and Menstrual cycle regulation.

IV. The Biology of Emotional Behavior.

A. Relevance of Medicine.

B. The tripartite characteristics of the Emotions.

C. The specificity and integrated nature of emotional behavior.

D. The communication of emotion.

E. The psychology of emotion.

1. Autonomic components.

2. Endocrine components.

3. Immune components.

F. The neurobiology of emotional behavior.

1. Pontine mechanisms.

2. Mid-brain mechanisms.

3. Hypothalamic mechanisms

4. Limbic mechanisms -

Septum

Amygdala

Cingulate gyrus. 
G. The integration of behavior and physiology.

Role of brain peptides.

V. The Biology of Learning and Memory.

A. Relevance for Medicine.

B. Types of Learning:

1. Simple: Habituation and Sensitization.

Neurobiology.

2. Associative learning: classical, operant, one trial (aversive).

a) Neurobiology.

b) Psychobiology. Conditioning of visceral responses.

3. Complex learning: Imprinting, latent, vicarious.

C. Memory.

Neurobiology:

Synaptic mechanisms.

New connections.

Peptides.

The hippocampus.

\section{The Second Year}

In the second year the student's view of medicine is biased further toward pathological anatomy and physiology: the classical topics of medicine which we owe to Morgagni, Bichat, Pasteur, and Virchow. The student's concepts of pathogenesis and etiology (frequently not differentiated) are directed toward their (outdated) unicausal nature in virology, bacteriology and genetics. A complex interactive model is rarely taught-one that incorporates the fact, for example, that the time of day a bacterium is injected into an animal determines the outcome. And, the immune system is taught as if it were a "Ding an Sich"-as if it operated in a vacuum, independent of the rest of the body.

But most seriously the student never learns that there is a "medicine without signs, "or that the greatest cause of morbidity and mortality in adolescence is the consequence of violence, alcohol ingestion and human error. To exemplify, figures on the reasons for physician visits in the U.S.A. in 1977-78 indicate the following: headache $\left(9 \times 10^{6}\right)$, weight gain $\left(6.2 \times 10^{6}\right)$, anxiety and nervousness $\left(6 \times 10^{6}\right)$, low back pain $\left(4.8 \times 10^{6}\right)$, depression $\left(4.5 \times 10^{6}\right)$, and tiredness and exhaustion $\left(4 \times 10^{6}\right)$. These are complaints that are most unlikely to have a pathological anatomy. Their diagnostic relevance and understanding are not taught-certainly not in the pathology laboratory, or in any course in the behavioral science or psychiatry that I know of. Should these data not be brought to the attention of the student immediately and tied to knowledge about behavior, and the 
impact of experience of human beings. I would suggest that this information be brought to the attention of students at a time when they are learning pathology, to counteract the impression that all illness is due to disease. Such a course might have the following content:

A. Medicine without signs.

1. A conceptual framework for Health, Illness and Disease.

2. The Nature of Illness.

3. The Epidemiology of Illness.

B. The Antecedents of Illness.

1. Natural Disasters and Danger.

2. Manmade Disasters.

3. Bereavement.

4. Unemployment.

5. Retirement.

C. Selective Pressures on Man

D. Their Consequences and their Psychobiology.

1. The post traumatic syndromes.

2. Grief and its consequences.

3. Responses to Danger.

E. Illness Behaviors \& Their Consequences:

1. Alterations in Food Intake.

Obesity and Anorexia.

2. Alterations of Liquid Intake.

Water Intoxication.

Alcoholism.

Diabetes insipidus.

3. Drug abuse.

4. Alterations in Sleep Patterns:

Fatigue.

Fibromyalgias.

Cardiovascular consequences.

5. Alterations of Cardiorespiratory Function.

Hyperventilation Syndrome.

Anxiety Syndromes.

6. Alterations in Bowel Function.

7. Alterations in Growth.

8. Headache.

9. Other pain syndromes.

10. Disturbances of action.

11. Alterations in Reproductive Function.

F. Prevention, Intervention and Treatment.

1. Support, Self-help groups. 
2. Relaxation.

3. Meditation.

4. Biofeedback in the specific illnesses-Epilepsy, hypertension, headaches, bowel disorders hyperventilation, etc.

\section{The Clinical Years: 1}

Clinical teaching has a very low priority in medical schools. ${ }^{12} \mathrm{~A}$ great deal of the teaching of students is left to the least experienced physiciansinterns, residents or fellows. Furthermore, in most major university centers, there has been a radical shift in the patient population: only the terminally ill have ready access-those with AIDS; malignancies (in the end stages or several at the same time; multiple system diseases; end-stage brain, renal or pulmonary disease, or exotically rare diseases. An atmosphere of therapeutic pessimism and hopelessness thus pervades the wards. Additionally, little attention is paid to the anxieties, discomforts, pains, griefs and hopelessness of patients and their families. Over and over again, because students and young physicians feel they cannot "do" anything-i.e. "cure" mortal disease - they turn away from patients. Their own grief, dimly recognized, is defended against by annoyance at, and or hardening of attitudes towards patients. I submit that no number of courses on ethics will teach students to be involved in the care of their severely ill or dying patients. Negative attitudes should be negatively reinforced immediately. And, the skills of recognizing grief and helplessness, etc. in themselves and in their patients should be taught. No amount of reading and lecturing substitutes for proper role modelling and focused teaching. Nor can compassion be left to chance; the skills that make compassionate physicians can be taught.

The early exposure of students to mortal, physical disease forces the student to embrace a narrow conceptual model of medicine-espoused by Seldin; ". . . . the relief of pain, the prevention of disability and the postponement of death. ..." ${ }^{13}$ Nothing in this definition of medicine is said about health maintenance, the prevention of illness and disease, rehabilitation, or helping patients to cope with disease, or to die gracefully.

\section{DISCUSSION}

The care of patients as people, and the recognition and tolerance of their distress requires a great deal of thought, experience and commitment. It is much easier to learn high-technology, dehumanized medicine, which is the model practiced on wards of academic centers. Cassell, ${ }^{14}$ has identified two additional and major issues in the clinical education of students. (1) A 
sophisticated concern with pathophysiology taught in medical school and the unexamined reliance on patterns of tests to substantiate the defects, leading to its "cook-book"; but not an integrated treatment of the patient. (2) A generation of teachers with clinical experience under their belts who have the responsibility, but not the authority to care for patients which the house officer has preempted.

What then can be done? It follows from the above that to focus exclusively on pathophysiology in the critically ill patient is to acquire an immediate bias which most students never relinquish. Thus the wards of university hospitals do not provide the best experience that would acquaint students with the illnesses for which most patients seek help. If students were initially exposed to a wide range of illnesses (not only disease), they would also be forced to acknowledge the preeminent role of social and behavioral factors in their etiology.

This exposure would impel the student to learn to gather data, not only about symptoms and signs of illness and disease, but about sick persons living in their social, familial and work environments. They should also be enjoined to learn to analyse their data, assess its reliability, explicate the process by which they reached diagnostic decisions, and learn to use laboratory data only as validating criteria and not as their main diagnostic tools. Above all they should systematically learn specific skills in recognizing the cognitive, emotional and personal responses of their patients, and learn to analyse the illness and disease. Such specific skills should be taught and continuously reiterated in the manner outlined by Engel: ${ }^{15}$

\section{Characteristics of the Symptom:}

A. How often or how continuous is it during the day or night?

B. When does it occur during the day etc; associated with what?

Time course (meals, at work, at home, exercise etc.)?

C. The nature of the symptom.

Describe how? (e.g. Pain: sharp, dull, continuous, intermittent; e.g. as a simile, metaphor, etc.)

D. What vital function, if any, does it interfere with?

II. Antecedent Factors:

A. Are there predromal symptoms?

(Aura, rapid heart beat, dry mouth, etc.)

Nature?

Duration?

B. Availability of relief?

C. Nature of medication?

Name of drug.

Amount taken.

When taken. 
D. Under what circumstances or conditions do these antecedent symptoms occur.

III. Contingent Factors:

A. Social Context of Symptoms:

Alone

With others.

B. Behavior during episode.

Stopped activity, etc.

Sought help.

Tried to relieve it.

C. Behavior after episode.

Continued activity.

Reported it or hid it, etc.

D. Behavior associated with symptom.

Appropriate

Inappropriate

E. Behaviors-actions, emotions, cognitions associated with

symptom:

Fear, shame, self-blame, etc.

F. Responses of others to symptom.

\section{CONCLUSION}

The teacher should at all times make explicit the relevance of this information for the diagnosis and care of the patient. The teaching of an integrated medicine is today honored only in the breach, in part because the entire training of young students and physicians takes place in an atmosphere of crisis, emergency, and impending death in tertiary care hospitals.

Rather, students should first be taught medicine in ambulatory care settings and emergency rooms. There they would acquaint themselves with the range of misery, distress, injury, and disease that are most commonly seen. In short, they must first learn what the content of medicine is, what doctors do and how patients function or do not, without first determining to what specialist they can "punt" the patient. The student should then follow his patient from the ambulatory setting to the in-patient or out-patient unit, in which the patient is next cared for. Students should initially have an extensive rather than intensive experience, paying particular attention to every aspect of the patient's functioning and care.

Students should have experiences in prenatal and well-baby clinics, in weight-reduction clinics etc. They should also be exposed to methods of changing behaviors, bad habits and modifying symptoms by behavioral and psychosocial means. 
A more intensive clinical experience with the hospitalized patient might occur in the fourth year, at no time neglecting the patient-oriented approach which hopefully the student will have acquired. This learning, must, however, at all times be reinforced by a broad approach to each patient that emphasizes: the relevance of the context in which the patient became sick, the nature of the disease(s) and how they are affecting the vital biological functions of the patient; the manner in which the patient is coping with his disease and whether the capacity to cope is impaired by altered language, cognition, mood or feeling states, an understanding of the present state of patients in terms of their personal histories and background, how all of this information is best used to care for patients and treat their disease, and a careful weighing of the effects and benefits (or not) of medications.

Such a revised curriculum will require much thought, and reorganization of training, the reeducation of faculties, and a much greater emphasis on the aim and process of medical education, in the face of a long tradition, inertia, and strong resistance to change.

\section{REFERENCE NOTES}

1. Josiah Macy, Jr Foundation: Graduate Medical Education Present and Prospective: Call for Action. New York: Josiah Macy Jr. Foundation, 1980.

2. Institute of Medicine: Medical Education and Societal Needs: A Planning Report for the Health Professions. Washington, D.C.: National Academy Press, 1983.

3. The President's Report: Harvard University, 1982-1983.

4. Eichna, L W: A medical school curriculum for the 1980s. $N$ Engl J Med 308:18-21, 1983.

5. Association of American Medical Colleges, Physicians for the Twenty-first Century. J Med Educ 59:1-208, 1984.

6. Committee on Medical Education, Symposium on the training of tomorrow's physicians: How well are we meeting society's expectations? Bull NY Acad Med 60:219-310, 1984.

7. Chin, D, Hopkins, D, Melman, K, Holman, H R: The relation of faculty academic activity to financing sources in a department of medicine. $N \mathrm{Engl} \mathrm{J} \mathrm{Med}$ 312:1029-1034, 1985.

8. Sierles, F, Hendrick, I and Circle, S: Cheating in medical school. J Med Educ 55:124-125, 1980.

9. Shapiro, M F, Charrow, R P: Scientific misconduct in investigational drug trials. N Engl J Med 312:731-736, 1985.

10. Patient's reasons for visiting physicians: National ambulatory care survey: United States 1977-78. Data from National Health Survey. Series 13, No. 56. DHHS Publication No. (PHS) 82-1717. US-DHHS NCHS Hyattsville, MD, 1981.

11. Lloyd, G: Medicine without signs. Brit Med $J$ 287:539-542, 1983. 
12. Swanson, A G, The medical school student and the faculty forest. Bull NY Acad Med 60:290-296, 1984.

13. Seldin, D: Quoted in Ref 3 op cit.

14. Cassell, E J, Practice versus theory in academic medicine: The conflict between house officers and attending physicians. Bull NY Acad Med 60:297-308, 1984.

15. Engel, B T: Fecal incontinence and encopresis: a psychophysiological analysis. In R Holzl and W E Whitehead (Eds) Psychophysiology of the Gastrointestinal Tract. New York: Plenum, 1983. 